\title{
Microplasma surfacing on turbine blades
}

\author{
Rashit Latypov*, Mikhail Silensky, and Gulnara Latypova \\ Moscow Polytechnic University, department "Equipment and technologies of welding production", \\ 115280, Russia
}

\begin{abstract}
In modern technologies for the production of turbine blades, plasma surfacing processes of various levels of automation are increasingly used. Plasma surfacing is applied to the working surfaces of critical parts in order to obtain zones with special physical and mechanical properties or restore the specified geometric dimensions, correct defects in the base material, etc. The design of the turbine blades must meet all the requirements of the product's service life, including long-term strength and creep, anti-friction characteristics under shock and alternating loads, corrosion resistance in fuel combustion products, etc. Plasma surfacing can help meet these requirements.
\end{abstract}

\section{Justification of the surfacing method}

To the greatest extent, technological and metallurgical problems of applying surfacing processes are complicated on blade materials ZHS-6, CHS-70, ZHS-32, CHS-88U and others related to the systems of alloying ultralight alloys[1]. Cobalt stellites of the B3K type are most often used as surfacing materials. with a hardness in the deposited layer of $45 \ldots 50$ HRC or relit. Their use only in the form of casting rods is possible only in manual arc technologies in protective gases, the main disadvantages of which are the instability of the heating process and the formation of surfacing, low quality and productivity.

In automated processes, they use both compact filler materials in the form of Inconel 625 wire with a diameter of $0.8 \mathrm{~mm}$ to restore worn surfaces and complex alloyed metal powders with a dispersion of $40 \ldots 100$ microns or piston wires with a diameter of 1.0 to 1.6 $\mathrm{mm}$ with additional gas protection providing HRC up to 65 units. Quite often, a given microhardness and a favorable working structure can be obtained not in the first, but in subsequent layers of surfacing. However, the general requirement in all cases is to ensure a consistently low heat input into the deposited zone, taking into account the significant difference in the physicochemical properties, composition and structure of the substrate materials and the deposited materials. This is also related to the need to solve metallurgical problems of the quality and operability of surfacing (cracks in the base and deposited metal, porosity, penetration depth of the substrate, or the size of the diffusion layer with areas of low-plastic structures).

According to the literature, a $400 \mathrm{~W}$ Nd-Yag solid-state laser was used to weld the ends of a single-crystal blade $1.3 \mathrm{~mm}$ in height in several passes using powder materials [2].

*Corresponding author: 1atipov46@mail.ru 
In this case, a dosed amount of powder is applied to a limited area of the molten spot at a consistent speed of movement of the part. The main disadvantages of such a scheme: uneven formation, a tendency to oxidation of the powder due to imperfect protection, and even the need for mechanical Stripping of the surfacing after each pass. In some areas, a significant number of cracks were recorded due to local overheating of the thin sections of the blade.

After weighing the advantages and disadvantages of manual arc, laser and microplasma surfacing, it turned out that the most suitable method is microplasma surfacing.

\section{Technology of the process of microplasma surface}

Arc plasma is an intense thermal effect with a wide range of technological properties. It should be noted that the current density in plasmatrons reaches $100 \mathrm{~A} / \mathrm{mm} 2$ and more, which is an order of magnitude higher than in a freely burning arc in shielding gases. A schematic diagram of the microplasma surfacing process is shown in Fig. 1

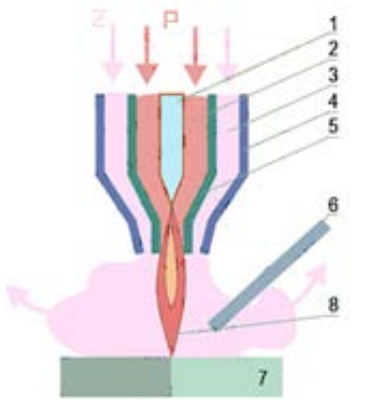

Fig. 1. Diagram of microplasma welding.

1 - Tungsten electrode; 2 - channel for supplying plasma - forming gas; 3 - channel for supplying protective gas; 4 - ceramic nozzle; 5 - nozzle of the plasma - forming channel; 6 - filler wire; 7 - parts to be welded; 8 - plasma; P-plasma-forming gas; Z-protective gas.

The arc plasma jet on the LAWS-500 installation is obtained according to the microplasma cladding scheme in a pulsed mode by changing the amplitude of the pulse current, the pilot arc current, their ratio and the pulse and pause time, and the adjustable form of the current rise in the pulse.

The plasma-forming gas is argon of composition A, GOST 10157-2016, the flow rate of which is accurately monitored by an electronic rotameter.

An argon-hydrogen mixture $\left(\mathrm{Ar}+5-6 \% \mathrm{H}_{2}\right)$ is used as a shielding gas. If the shielding gas is argon, the arc is cylindrical or slightly widening towards the anode. The same shape of the arc is retained when it exists at currents higher than $20 \mathrm{~A}$, since the effect of the shielding gas on the compression of the arc is noticeably weakened [3].

The cathode is a lanthanum tungsten rod with a diameter of $1.2 \mathrm{~mm}$, with increased thermal stability and emission properties.

\section{Plasma system}

Installation LAWS-500 Fig. 2 is designed for automated microplasma surfacing on the ends of blades made of special materials in the form of flux-cored wires or wires of solid section. The installation allows to fully automate the surfacing process along the programmed trajectory of parts of complex configuration in the X, Y, Z coordinates $(460 * 460 * 300 \mathrm{~mm})$. 


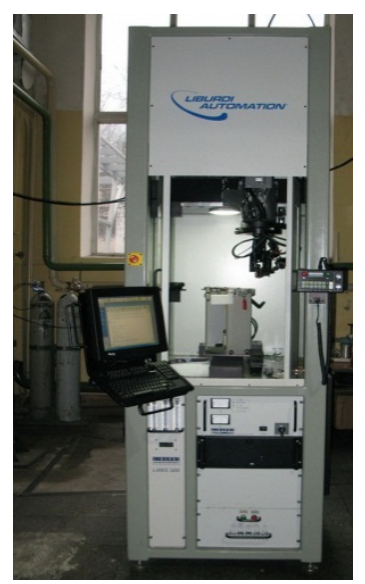

Fig. 2. General view and composition of the LAWS-500 installation.

Affiliations of authors should be typed in 9-point Times. They should be preceded by a numerical superscript corresponding to the same superscript after the name of the author concerned. Please ensure that affiliations are as full and complete as possible and include the country.

The part to be surfacing Fig. 3 (sample, blade) is installed and fixed along the profile in cooled copper plates with a protrusion of up to $0.8+0.1 \mathrm{~mm}$. There is a device for additional protection and cooling with a protective gas of the lower zone of the part adjacent to the surfacing.

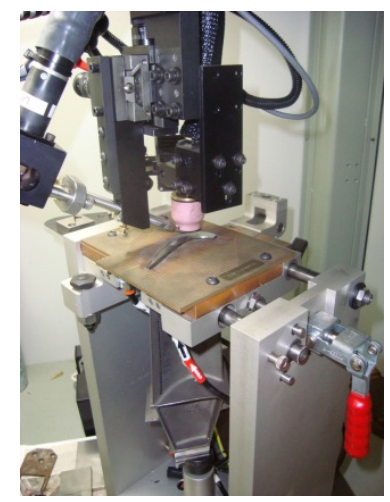

Fig. 3. Part to be surfacing blade.

\section{Obtaining a surfacing layer}

The main task was to obtain a two-pass or three-pass surfacing, providing the required cross-sectional dimensions after erosion treatment, taking into account the need for minimal heat input into the base material of the blade, taking into account a number of possible difficulties on difficult-to-weld blade materials, the tendency to crack formation in the substrate and deposited layers.

A feature of the LAWS-500 installation is the presence of a vision system that allows you to track the blade profile and find the points of the surfacing trajectory in the specified search segments. 
Preliminarily, the trajectory of surfacing at the blade end was divided in the X, Y plane into separate segments, necessarily in areas with variable curvature. In fig. 4 shows the real configuration of the blade with the numbers of the trajectory sections.

As a result, work was carried out to strengthen the ends of the rotor blades from the ChS-88U alloy with a Stelkay 1-G flux-cored wire, $1.2 \mathrm{~mm}$ in diameter, Fig. 4-6.

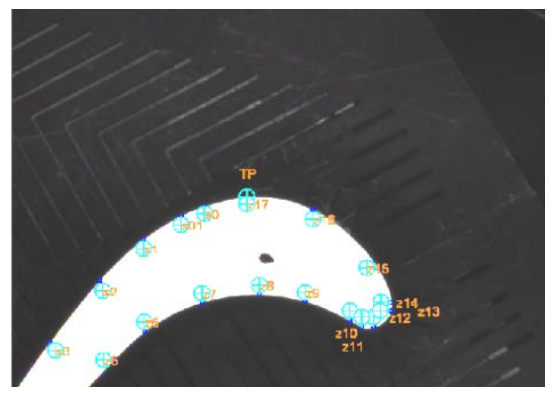

Fig. 4. Example of dividing the contour of the end of the blade into segments.

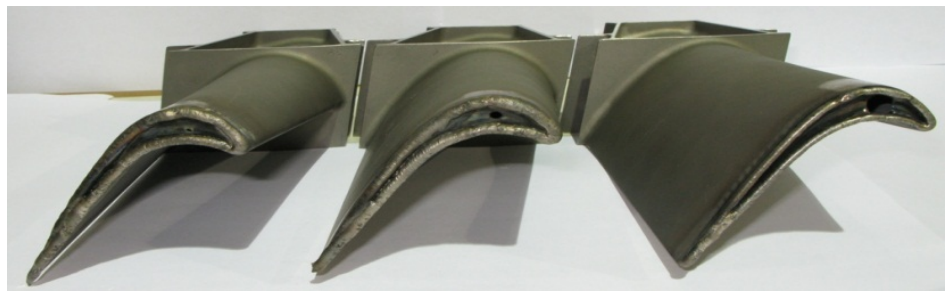

Fig. 5. Appearance of the blades after three-pass surfacing.

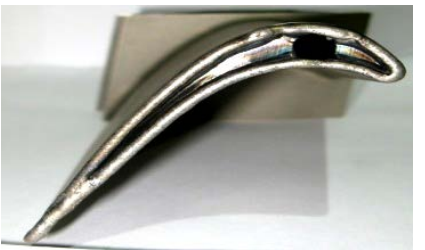

Fig. 6. Appearance of this blade after two-pass surfacing of the radius end face.

\section{Structure of the surfacing layer}

Metallographic study of two-pass and three-pass surfacing, the maximum depth of penetration into the substrate is 0.5 and $0.35 \mathrm{~mm}$, respectively. Along the edges of the surfacing, fusion is noted without lack of penetration and cracks with a microhardness in this zone of $50 \mathrm{HRC}$.

In the deposited metal, a single porosity of no more than $0.1 \mathrm{~mm}$ is noted. Macrodefects such as cracks, lack of fusion between layers or with the base metal were not found.

The macrostructure of the deposited layers has the character of a dendritic structure of various degrees of dispersion and with a wide spread of microhardness 55-65 HRC

Taking this into account, it becomes necessary to search for or develop surfacing wires providing a homogeneous distribution of the main strengthening components $(\mathrm{Cr}, \mathrm{W}, \mathrm{C})$ and $\mathrm{Co}$ as a base and a smaller spread of microhardness.

In Fig. 7 shows the results of the above metallographic studies. 


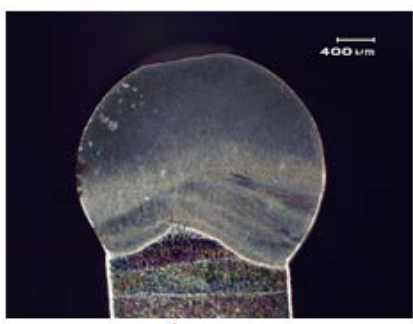

a)

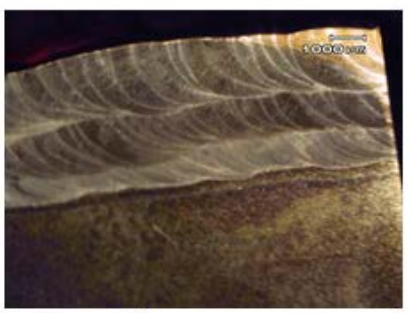

c)

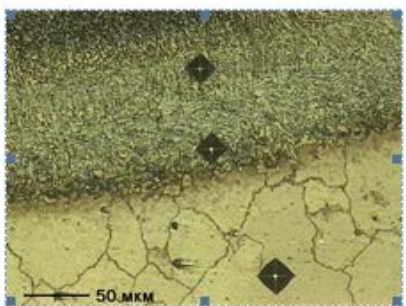

d)

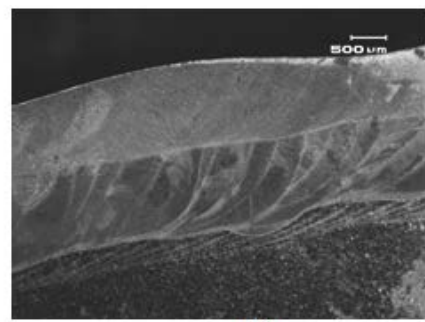

b)

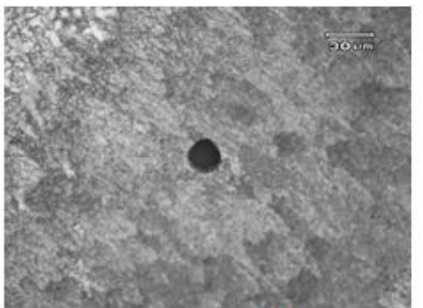

e)

Fig. 7. Metallographic studies.

a - cross section of a two-layer surfacing, b - longitudinal section, c - longitudinal sections of a three-layer surfacing, $\mathrm{d}$ - interface structure, $\mathrm{e}$ - porosity $\varnothing 0.1 \mathrm{~mm}$.

\section{Conclusions}

1. According to the worked out modes, two-pass and three-pass surfacing with flux-cored wires on a cobalt base on rotor blades were performed with confirmation of the main dimensions of the section.

2. A number of metallographic studies of macro and microstructures of surfacing have been carried out

3. No defects affecting the operation of the product were found.

\section{References}

1. Stroyeniye i aviatsionnykh materialov: Uchebnik dlya vuzov Belov A.F., Benediktova G.P., svoystva Viskov A.S. i dr. Pod red. akad. Belova A.F., dokt. tekhn. nauk, prof. Nikolenko V.V. M .: Metallurgiya, 1989. 368 s.

2. Vliyaniye tekhnologicheskikh parametrov gazoporoshkovoy lazernoy naplavki na strukturnyye kharakteristiki vosstanovlennogo poverkhnostnogo sloya korrozionnostoykikh staley / S. Ye. Krylova [i dr.]. // Metallovedeniye i termicheskaya obrabotka metallov. 2017. № 10 (748) s. 35-40.

3. Plazmennaya naplavka metallov. / Vaynerman A.Ye., Shorshorov M.KH., Veselkov V.D., Novosadov V.S .: Mashinostroyeniye, 1969 g., 19 s. 